\title{
Twitter as a Tool for and Object of Political and Electoral Activity: Considering Electoral Context and Variance Among Actors
}

\author{
Shannon C McGregor \\ Rachel Mourao \\ Logan Molyneux
}

\begin{abstract}
In recent years, journalists, political elites, and the public have used Twitter as an indicator of political trends. Given this usage, what effect do campaign activities have on Twitter discourse? What effect does that discourse have on electoral outcomes? We posit that Twitter can be understood a tool for and an object of political communication, especially during elections. This study positions Twitter volume as an outcome of other electoral antecedents and then assesses its relevance in election campaigns. Using a dataset of more than 3 million tweets about 2014 U.S. Senate candidates from three distinct groups - news media, political actors, and the public - we find competitiveness and money spent in the race were the main predictors of volume of Twitter discourse, and the impact of competitiveness of the race was stronger for tweets coming from the media when compared to the other groups. Twitter volume did not predict vote share for any of the 35 races studied. Our findings suggest that Twitter is better understood as a tool for political communication, and its usage may be predicted by money spent and race characteristics. As an object, Twitter use has limited power to predict electoral outcomes.
\end{abstract}

Keywords: digital trace data; Twitter; political communication; electoral prediction; public opinion 
Social media have made it easy for various publics to record and share their opinions, including about politics. Political science scholars worldwide have therefore tried to use Twitter data to predict electoral outcomes or public opinion (see Gayo-Evello, 2013; Jungherr, 2015; Mitchell \& Hitlin, 2013). At first blush, it appeared that Twitter data may have impressive predictive power for electoral outcomes (O'Connor et al., 2010; Tumasjan et al. 2010), but Fanelli (2010) points out the tendency against reporting negative results in this line of research. Scholars disagree on how best to approach these questions methodologically (Jungherr et al., 2010; Gayo-Evello, 2013).

It is likely that the volume of tweets is a better indicator of attention than opinion or support, since traditional public opinion is often at odds with the nature of conversations on Twitter (Jungherr, Schoen, Posegga \& Jurgens, 2016; Mitchell\& Hitlin, 2013). But attention is often a feedback loop among political information brokers (campaigns and their proxies on one hand, news media on the other) and the general public. These groups do not hold equal sway over the Twitter conversation - Twitter is not analogous to the general public, nor is it a homogenous group of social media users. It's well documented that a small but active subset of political and media actors drive political discussions (Wu et al., 2011; Parmelee, 2013), despite affordances of Twitter (like a chronological timeline) that work against bias introduced by a filtering algorithm.

Our study aims to address some of these concerns, while also introducing new concepts and seeking to identify circumstances under which Twitter discourse is related to electoral outcomes. First, we break Twitter users into three groups that are likely to be most relevant during an election campaign: the news media, political actors, and the public. Second, we consider how the attention a candidate receives on Twitter might be related to that candidate's 
contextual characteristics like incumbency and competitiveness of the race. Finally, we assess the unique impact of Twitter discourse on electoral outcomes by controlling for other factors affecting them both, including incumbency, money spent by candidates, and the competitiveness of the race. This study uses data collected during the 2014 campaigns for United States Senate, providing a range of political perspectives and various levels of attention to 70 candidates in 35 races that year.

Measuring Twitter's predictive power in elections is important regardless of its strength. If Twitter can predict electoral outcomes, then its content may be used as a real-time supplement to traditional polling. If Twitter content does not relate to electoral outcomes, then why do campaigns, political media and researchers make so much of it? And what are the potential effects for the voting public? This study seeks to situate Twitter discourse among other electoral antecedents and contribute to an understanding of its relevance in election campaigns.

\section{Twitter and Elections}

One of the unique characteristics of social media is the relative inclusion of voices from a variety of publics. This is especially apparent on Twitter where a chronological feed and the ability to follow tweets outside your network via a hashtag or keyword afford users the ability to see tweets from the news media, political actors, and other members of the public. In the Twittersphere, traditional journalists intermingle with bloggers, the public and the candidates themselves to produce a vast array of electoral commentary. Because it is a hub of activity, Twitter receives heightened attention from political and media elites. In this way, Twitter can be seen as both a tool for and object of political communication. It provides a platform for the media, political actors and the public to communicate while also providing fodder for their communication - information is simultaneously, yet differentially, relayed and received by all 
parties. As a tool for political communication, Twitter allows political elites to campaign, journalists to construct narratives, and the public to share their opinions about candidates and processes. As an object, Twitter serves as an input for those three groups to direct their attention, vote, strategize campaigns, etc.

The following section lays out the various ways in which these three types of actors utilize Twitter as a tool for and an object of communication, albeit with differing uses within this overarching schema.

News Media. The news media and journalists took quickly to Twitter, recognizing it as a tool for telling stories but also an object of the news itself (Lasorsa, Lewis \& Holton, 2012). Reporters of all types, including political journalists, increasingly rely on the platform and are often required to incorporate tweets into their coverage (Farhi, 2009; Hermida, 2010; Lawrence, Molyneux, Coddington \& Holton, 2014). Many news organizations employ social media engagement editors whose role is to both oversee the outlet's social media presence as well as to take advantage of the personalized nature of social media sites to foster a relationship with the public (Wasike, 2013). Furthermore, journalists interact with one another on Twitter to construct narratives (Mourao, 2015). Evidence points to a hybrid relationship between Twitter and more traditional news mediums (Chadwick, 2013; Jungherr, 2015). “Twitter's environment during elections is less about predicting election outcomes or tracking campaign popularity, but, in the American contest, more a niche media environment” (Murthy, 2015, p. 829). But we cannot relegate it to the sidelines, as campaigns and candidates are spending record money on digital efforts (Willis, 2014), and Twitter is increasingly covered as a news object and used as a source by more traditional media, especially in electoral contexts (Lawrence, 2012). The U.S. news media's heavy use of Twitter is what sets it apart from other social media. While Facebook and 
YouTube have larger user bases, some of whom get news and conduct political activity there, Twitter is the most popular social platform among U.S. journalists, with 71 percent saying they use it regularly (Cision, 2015). This makes it particularly well suited for this study's focus on social media as a tool for and an object of political communication.

Political Elites. For political actors, Twitter is a tool that offers a variety of functions. Some scholars contend that parties and candidates use Twitter to "go around" the news media, reaching straight for voters (Parmlee \& Bichard, 2012; Stromer-Galley, 2014). On the other hand, Kreiss (2014) finds that campaign staffers used Twitter in explicit attempts to influence the "agendas and frames of professional journalists" (p. 1). Political actors also use Twitter to mobilize the base (Kreiss, 2014) and to achieve wider attention (Parmlee \& Bichard, 2012). Candidates tweet using traditional communication styles, like campaigning and policy, but also, to varying degrees, take advantage of the particular affordances of the site to personalize themselves, much in the way we all do on social media (Gainous \& Wagner, 2014; McGregor, Lawrence \& Cardona, 2015; Meeks, 2014). Transitioning from production to consumption, Twitter also serves as an object of communication for campaigns. Especially in elections, candidates react and respond to an almost ceaseless stream of tweets from their opponents, whereas the tweets themselves take on greater importance by becoming objects of communication. Furthermore, political elites use sentiment on Twitter as a proxy for public opinion (Baldwin-Philippi, 2015; Chadwick, 2013).

General Public. Although its user base is not representative of the U.S. public (or any country's population), Twitter does provide a means by which individuals may express their political opinions. The number of Americans using social media for political communication is on the rise - Pew (2016) reports that 44 percent of U.S. adults used social media in the past week 
to learn about the 2016 presidential election ${ }^{1}$. About a third of U.S. adults have taken at least one civic or political action within social media (Pew, 2012). Using social media even for relational purposes can lead one toward political expression on social media (Gil de Zúñiga, Molyneux \& Zheng, 2014), and half of Twitter users report getting news from the site (Pew, 2015). Some supplement television news with Twitter - second screening specifically to get more information about and to discuss issues in the news (Gil de Zúñiga, Garcia \& McGregor, 2015). Twitter use spikes around campaign events (Freelon \& Karpf, 2015; Jang \& Pasek, 2015); for example, 1 in 10 people second screened during the first debate between Mitt Romney and President Barack Obama (Pew, 2012). Importantly, Freelon and Karpf (2015) examine debate tweets and find that Twitter can be inclusive of non-traditional political voices. In summary, the general public uses Twitter both as a tool to express political opinions and as a source of political information.

The media, political elites and the general public all have different uses for and interactions with Twitter, as explained above. Two key methodological choices stem from these observations. First, we argue that not all tweets are created equal. Centrality and influence measures from network analysis indicate that some actors, particularly media and political elites, are more influential on social networks than are the general public (Parmelee, 2013; Wu et al., 2011). While some have noted this difference, analysis of posts on Twitter generally proceeds as if Twitter users are a homogenous group of equally powerful individuals. Thus we find it important to treat each of these groups (the media, political elites, and the general public) separately in order to assess the impact of their Twitter discourse.

Second, because we conceptualize Twitter as both an object of political information and a tool for political expression, this study treats Twitter discourse from these three groups as both a

\footnotetext{
${ }^{1}$ We acknowledge that this percentage is likely to be lower during a mid-term Senate election, as is the setting for this study.
} 
dependent variable and an independent variable. Traditional campaign activities such as buying advertising and organizing town hall meetings are meant to raise awareness and garner support for a candidate; social media may be seen as both a source of feedback to measure the effectiveness of these strategies as well as an arena in which campaign activities may be carried out digitally.

We assess the media, political, and public use of Twitter as a tool that may indicate attention to candidates, and we examine how these measures are associated with known antecedents of senate electoral victory (and thus attention): incumbency (Cummings, 1966; Stokes \& Miller, 1962; Erikson, 1971; Erikson \& Palfrey, 1998), competitiveness (Abramowitz, 1988; Jacobson \& Carson, 2015; Westlye, 1983), and money spent (Jacobson \& Carson, 2015; Gerber, 1998). Furthermore, based on previous research that has identified differential uses of Twitter between parties (Colleoni, Rozza \& Arvidsson, 2014; Conover, Goncalves, Flammini \& Menczer, 2012; Conway, Kenski \& Wang, 2013; Kreiss, 2015), we include political party as a variable in the model, both to examine differences but also as a control in models, as the 2014 Senate election was overwhelmingly one of Republican victories. If Twitter is used as a tool for political communication about candidates, we may expect it is related to other measures of attention to a race like money spent or competitiveness. Additionally, if the relative volume of tweets about a candidate is associated with electoral victories (the focus of our second research question), then tweet volume should be related to these electoral antecedents. Thus as a first step, this study poses the following research question using Twitter discourse as a dependent variable (what predicts its use as a tool for).

RQ1: How are incumbency, competitiveness, money spent and party related to the volume of Twitter discourse among (a) political actors, (b) news media and (c) the general public? 


\section{Using Twitter to Predict Elections}

Both Gayo-Avello (2013) and Jungherr (2015) provide comprehensive overviews of scholarly work examining the role of Twitter in electoral prediction. Gayo-Avello (2013) presents a meta-analysis of work on this topic; likewise, in his book, Jungherr (2015) provides a helpful schema of relevant studies in this field, aggregating the various independent and dependent variables used, as well as varying methodologies ${ }^{2}$. After reviewing the literature, both works come to analogous conclusions: methodological problems abound, suggesting that Twitter is unlikely to replace traditional polling anytime soon.

The relatively easy access to so-called behavioral residue on online systems like Twitter has prodded scholars to use these large data sets to predict both present and future events (GayoAvello, 2013). Some of the first studies using Twitter data to predict elections found a positive relationship. Tumasjan and colleagues (2010) suggested that tweet volume and actual voters were strongly correlated, and O'Connor et al. (2010) found a positive relationship between tweets and public opinion polls. However, these studies were not without criticism. Jungherr, Jurgens and Schoen (2011) raised objections to Tumasjan et al. (2010) based on methodological issues. In fact, much of the criticism leveled at (and within) this area of research focuses on methodological issues (see Gayo-Avello, 2013; Jungherr, 2015).

As Jungherr (2015) points out, many studies were conducted after the election they aim to predict (e.g. O'Connor et al., 2010; Rojas, 2013; Tumasjan et al., 2010). Ours also is a posthoc analysis, but we are careful to avoid saying our data predicted the 2014 elections. Where relationships exist, they are important insomuch as they underpin the function of Twitter within electoral contexts.

\footnotetext{
2 They also both make criticisms of previous work, as well as suggestions for future studies, which we address later in this section.
} 
Some studies in the sub-field have been criticized because of their Twitter API choice. Those accessing the Twitter Search API are subject to algorithm bias in selecting only a portion of all available tweets for analysis (Gayo-Avello, 2013). This study uses a service that has access the Twitter firehose, which quells at least that concern. Still, Twitter users may not be representative of the public, but tweets collected via the firehose (as ours are) are not subject to sampling. Rather, they are the whole stream of tweets that match a given query and date range. Further, we present a rationale for choosing the data collection range.

Another line of criticism stems from the lack of a theoretical underpinning to studies attempting to assess Twitter as a reflection of public opinion (Jungherr, 2015; Margolin, Goodman, Keegan, Lin \& Lazer, 2015), and more specifically, "their implicitly assumed mechanism by which specific metrics of Twitter data should be connected with specific metrics of public opinion" (Jungherr, 2015, p. 189). That is, it is not clear why tweeting about a candidate should translate into a vote for that candidate. Many motivations to tweet about a candidate exist that bear no relationship to electoral support, some discussed in the previous sections.

Actors from any of the three groups on which we focus our inquiry may tweet about a candidate for a variety of reasons, some of which may be related to electoral outcomes. For example, news media tweets about candidates may indicate salience, which could foretell electoral success. In all cases, it makes sense to relate volume, or a simple count of how many times a candidate is mentioned, to electoral outcomes. That relationship is the focus of an additional research question in this study (Twitter as an object of political communication). RQ2: How is the volume of Twitter discourse about candidates among (a) political actors, (b) news media, and (c) the general public related to their performance in the general election? 
These research questions have been designed to address shortcomings in previous literature reviewed here; namely, treating Twitter as a homogeneous group and forcing it into a singular role as an independent variable. Taken together, our questions differentiate between user types on Twitter and account for different motivations they might have in tweeting about political candidates before relating these variables to electoral outcomes. Not only do we believe that this method more clearly represents the hybrid media environment (Chadwick, 2013), but also that it allows us to hone in on the locus of correlation. The fundamental questions we aim to answer here are how these different voices respond to traditional electoral activities and how these voices might relate to electoral outcomes.

\section{Methods}

For this study, we collected data from multiple sources in order to form a dataset capable of answering our research questions. The first step was to select an election with enough data points and enough interest from the public and the media to provide for a rich analysis. The 2014 elections for U.S. Senate fit this purpose. In all, 229 candidates vied for 36 seats. These candidates attracted more than $\$ 608$ million in funding, or almost $\$ 2.7$ million per candidate, ${ }^{3}$ according to data released by the Federal Election Commission. We chose to focus on the two primary contenders for each seat, usually one Republican and one Democrat, ${ }^{4}$ because these attracted the most attention and were the most viable contenders for the seat. In one state, Alabama, a candidate ran unopposed, so this race was removed from the analysis. In all, data was collected on 70 candidates vying for 35 Senate seats in 2014.

\footnotetext{
${ }^{3}$ This is more than 3.6 times the amount raised per candidate for seats in the U.S. House of Representatives. Furthermore, donations from individuals to Senate candidates outstripped those to House candidates by a factor of 4.7. These figures are presented as a straightforward way to compare nationwide interest in Senate and House races. ${ }^{4}$ The dataset includes one independent candidate, Greg Orman, who was the primary contender against the incumbent Republican Pat Roberts in Kansas.
} 


\section{Candidate Data}

For this study, we relied on two types of data: publicly available data about the candidates and the elections as published in news media, the Federal Election Commission, and other reports; and data collected from Twitter using Crimson Hexagon $(\mathrm{CH})$, a suite of social media analysis tools that provides access to the Twitter firehose (i.e. all public posts made on Twitter).

Election data. The dataset includes several variables relating to each candidate. Incumbency, competitiveness of the race, and money spent were used as control variables given their relation to electoral outcomes as established in previous literature. Whether a candidate won or lost and the share of the vote a candidate secured were both used as outcome variables in different statistical analyses.

Incumbency. This variable was a simple dummy variable to indicate incumbent status. Each incumbent candidate was coded 1, and challengers or those vying for open seats were coded 0 .

Competitiveness. The Cook Political Report rates each political contest according to competiveness. These ratings are based on the state's history, the stability of the incumbent, and the strength of the challenger. The races were rated 0 (safe), 1 (likely), 2 (leaning), or 3 (tossup).

Money spent. Financial data about U.S. Senate races is collected by the FEC and published on www.opensecrets.org. This site provided data on how much money each candidate raised and how much was spent. These have been used in previous studies as predictors of electoral success (Erikson \& Palfrey, 1998).

Voting results. Voting results were collected using election results published by The New York Times (2014). This included raw vote totals for each candidate as well as an overall total number of votes cast in the senate election. This was important in calculating vote share, 
one of the principal outcome variables in our analysis. The other outcome variable was whether a candidate won or lost the election, coded 1 for a win and 0 for a loss.

\section{Twitter Data}

This study measures the volume of Twitter chatter about each candidate from three distinct sources: the news media, political actors, and the rest of the general public. Previous studies have suggested that the news media and political actors form an elite circle of information sharing surrounding elections (Parmelee, 2013; Wu et al., 2011), so in order to accurately measure the tweeting public's interest in a candidate, it was important to separate these two elite groups from the main tweet stream. To do this, we created a list of media Twitter handles and a list of handles for political elites.

News media. The first step in identifying news media that cover politics was to use a database of media contacts curated by Cision, which has maintained media listings in the U.S. for more than 75 years. The database was searched by state for those covering politics. Many of these listings included Twitter handles for the journalists, and Internet searches were used to attempt to find handles for those without one listed. Internet searches were also used to determine the Twitter handles of all the organizations that these journalists worked for (as, for instance, the Denver Post tweets about the political stories its political reporter covers). These handles were used to create a media list for each state, 35 in all. These state-level media lists were used in addition to national-level media lists used in other studies (Lawrence, Molyneux, Coddington \& Holton, 2013; Lasorsa, Lewis \& Holton, 2012 $2^{5}$. For example, when measuring media chatter on Twitter regarding an election in Colorado, the national media list and the

\footnotetext{
5 The authors are currently underway on an update of this study, Normalizing 2.0. In service of this, the authors repeated the collection of the top-500 most influential U.S. journalists on Twitter, as calculated by Muckrack, for the year 2014. It is from this 2014 list that we add to our media list.
} 
Colorado media list were both employed. The final lists contained 3,418 Twitter handles for political journalists and news media outlets in the U.S.

Political elites. Creating a list of Twitter handles for political elites in each Senate race began with each campaign's official handle(s) (found by following social media links from the campaign's official website), the handles for both state parties, and the handles for both national parties (Republican and Democratic). To these were added Twitter handles for the top 20 organizations spending money on the race in question, as recorded by www.opensecrets.org. These handles included many PACs, SuperPACs and other lobbying organizations at both the state and national levels. The final list contained 314 Twitter handles for political elites. When collecting political elite tweets about an election, this master list was utilized.

The public. In order to gather tweets from the public, the previously described lists for the media and political elites were combined into a master "blacklist." Within $\mathrm{CH}$, it is possible to run a query where all tweets matching the search are retrieved, except for tweets from Twitter users whose handle is on the "blacklist." In this way, we gathered data from Twitter users we deemed to be public. Neither the media nor the political elite lists can said to be definitively exhaustive (that is, including every journalist tweeting about the elections or every political actor). To address this shortcoming, the lists were amended when analysis of the general public Twitter stream began. The Crimson Hexagon analysis tool (explained in more detail below) identifies "top authors" whenever an analysis is conducted. Whenever journalists, media entities, or political actors appeared as "top authors," that Twitter handle was added to the appropriate list and the analysis was re-run. Even if the lists are not exhaustive, they are at least mutually exclusive. The media list contains only journalists and news outlets, the political elites list contains only those identified as such, and those on both lists were excluded from analyses of the 
general public Twitter stream. By identifying these three groups, this study moves beyond treating Twitter as a homogeneous entity in order to examine the effects of the hybrid media atmosphere.

\section{Data Collection}

Twitter posts were collected using Crimson Hexagon $(\mathrm{CH})$, a suite of social media analysis tools that has access to all public posts on Twitter (Hitlin, 2013; Hopkins \& King, 2010; Pew, 2012). $\mathrm{CH}$ accesses the full firehose of Twitter, which allowed us to collect a full, rather than sampled, data set; some scholars have voiced skepticism towards Twitter's claim that the $\sim 1$ percent of data collected via the open API access is statistically representative (Morstatter, Pfeffer, Liu \& Carley, 2013). Gathering data on $\mathrm{CH}$ consists of creating a search string that will return all tweets matching that string. To capture tweets about each candidate, a Boolean query included that candidate's name, Twitter handle, and associated political hashtags. For example, the Joni Ernst query included: @ joniernst OR (\#iasen Ernst) OR “Joni Ernst”. The same pattern was used for each candidate in the sample. In all, three queries were run for each candidate: one gathering only tweets from media accounts, a second gathering data from only political elite accounts, and a third gathering tweets from the public.

Tweets were collected during the standard election cycle - September 1 to November 3 (the day before election day). This search period was used based on the recommendations of previous studies (Gayo-Avello, 2013; Jungherr, 2015). Additionally, including a primary period in the data collection may needlessly bias the data towards partisans, whereas we assume that those partaking in political discussion during the general election period may be less partisan; at the least, they represent a more equal distribution of party identification compared to those 
during a primary period. $\mathrm{CH}$ then queries Twitter for tweets containing the string and provides a standard set of analyses, including the volume (or raw total) of tweets about each candidate.

Volume. This is a simple count of the number of tweets referencing a candidate. It is possible to vary this number by altering the date range or the search string, so this count is reliable to the extent that the search string used for each candidate is exhaustive and consistent.

The volume of tweets about each candidate was recorded for each of the three groups: the media, political elites, and the rest of the general public. The volume of media posts about candidates ranged from 4 (Joyce Dickerson) to 4,467 (Mitch McConnell) (M=754.41, $S D=1029.79$ ). The volume of political elite posts ranged from 1 (Dickerson) to 1,616 (Ed Gillespie) $(M=312.76, S D=347.15)$. The volume of posts from the general public ranged from 79 (Campbell Cavasso) to 303,378 (McConnell) $(M=43,785.99, S D=66,730.86)$. In all, a total of 3,139,721 tweets were analyzed.

\section{Data Analysis}

Before directly answering our research questions, $t$-tests were conducted to assess the difference in the mean of volume of social media conversations about candidates who won and candidates who lost the elections. RQ1 examines how the volume of social media tweets is associated with a candidate's contextual characteristics. First, zero-order Pearson's correlations were performed to assess the way in which all variables of interest (incumbency, competitiveness, money spent, media volume, political elites volume, public volume, and vote share) are related to each other. Then, multiple linear regression models were estimated where the dependent variables were volume of media, political elites, and public separately. Variables were entered in two blocks. The first one contained the political characteristics of the candidates and the race (incumbency status, competitiveness of the race, money spent, and party affiliation). Then, the volume of the 
other political groups was entered to assess how variables influence volume stemming from a specific group beyond the volume of the other two others.

To answer RQ2, we estimate multiple linear regression models where Twitter volumes across the three groups become independent variables of interest and the dependent variable is vote share ${ }^{6}$. To address the issue of independence of observations between 70 candidates in 35 races, this analysis was conducted while splitting the sample into Republican and Democratic candidates ${ }^{7}$.

\section{Results}

Our inquiries examine how candidates' characteristics relate to volume and tone of Twitter discourse, and how such discourse relates to electoral outcomes. Table 1 shows the descriptive statistics of Twitter volume, split by candidates who were winners and losers in the 2014 mid-term election. Results presented in Table 1 reveal that, while the volume of tweets for winners was higher than the volume for losers among all three groups, (media: $M=841.17, S D$ $=1092.77$ for winners, $M=667.66, S D=970.83$ for losers; political elites: $M=315.23 S D=$ 289.47 for winners, $M=310.29 S D=400.95$ for losers; public: $M=47,521.63 S D=66,290.75$ for winners, $M=40,050.34 S D=67,924.90$ for losers), none of these differences are statistically significant. While this dichotomous categorization (winners versus losers) can be useful to examine differences between the two groups, for the linear regression models that answer the research questions, this paper uses vote share as the dependent variable. This provides more nuance and allows for the comparison not only between but also among the two groups.

\footnotetext{
${ }^{6}$ Before performing statistical analyses, assumption tests detected skewness and kurtosis slightly beyond acceptable scores. To address this issue, log transformations were performed on the dependent variable following the recommendation of Tabachnick and Fidell (2007).

7 For each race, a candidate's vote share is exactly $100 \%$ minus his/her opponent's share. Because all the races in this sample were between a Republican and a Democrat candidate, we addressed this issue by splitting the sample into the two groups and conducting separate regressions for each of them.
} 


\section{[Table 1 here]}

Results in Table 2 show zero-order correlations between the control variables, independent variables of interest, and the dependent variables. As expected, all groups' volumes were significantly correlated with the competitiveness of the race (media: r=.674; political elites: $\mathrm{r}=.666$; and public: $\mathrm{r}=.562$, all $p<.001$ ) and money spent (media: $\mathrm{r}=.635$; political elites: $\mathrm{r}=.541$; and public: $\mathrm{r}=.689$, all $p<.001)$. It is also interesting to note that volume of Twitter conversations about candidates were highly correlated among the three groups of Twitter users: the media, political elites, and the public. The public's volume of tweets about a candidate was almost perfectly correlated with the media's volume of tweets about that candidate $(r=.911, p<.001)$. The results from this correlation table suggests that public and media volume were more in sync with each other than either of those groups were with political elites' volume.

[Table 2 here]

To address the core question of what influences Twitter volume about a candidate (Twitter as a tool for political communication), RQ1 asks about the relationship between incumbency, competitiveness, money spent and party, and the volume of Twitter discourse among (a) political actors, (b) news media and (c) the general public. Multiple linear regression estimates reveal that competitiveness of the race $(\beta=.454, p<.001)$ and money spent $(\beta=.489, p<.001)$ are the main predictors of volume of Twitter conversations about a candidate among media actors (see Table 3). For the public, money spent $(\beta=.562, p<.001)$ had a much larger impact on volume of conversation when compared to competitiveness of the race $(\beta=.394, p<.05)$. For political elites, money spent $(\beta=.518, p<.001)$ was also a stronger predictor of volume as compared to competitiveness of the race $(\beta=.372, p<.01)$. The first set of political variables explained $66.9 \%$ of the variance for media volume, $56.9 \%$ for political elites' volume, and $69.4 \%$ for public. 
When the volume of the other groups was entered in Block 2, results reveal that they were strong predictors of each other's volume as expected. Only in the model for "public volume" did money spent remain a significant predictor even when considering the volume of the other two groups. In other words, volume of public tweets can be explained by money spent beyond the impact of that variable on volume of media and elites' tweets ${ }^{8}$.

The final models explained $90.3 \%$ of the media volume, $74.6 \%$ of political elites' volume, and $91.5 \%$ of the volume of tweets from the public. There were no statistically significant differences between incumbents and challengers, or Republicans and Democrats when it comes to volume of Twitter conversations. Taken together, these results suggest that money spent is the most significant predictor of Twitter volume for the three groups. However, this impact is smaller for tweets coming from journalists and news organizations when compared to the other two groups. In predicting volume of tweets stemming from the media, competitiveness of the race is as strong of a predictor as money spent, which is not observed to the same extent in tweets coming from the public or political elites.

Finally, research question 2 assesses the relationship between the volume of conversation on Twitter and vote share. Table 4 summarizes multiple linear regression models for volume of Twitter discourse about candidates among (a) political actors, (b) news media, and (c) the general public, and the dependent variable "vote share" (RQ2) split by party. Across the board, incumbency was the strongest predictor of vote share $(\beta=.534, p<.01$ for Republicans, and $\beta=.659, p<.001$ for Democrats in the final model). Volume of Twitter conversations was not statistically related to vote share for any group. The final model considering the total volume of Twitter content about a candidate explained 40.6 percent of the variance in vote share for

\footnotetext{
${ }^{8}$ VIF tests for media and public volume as independent variables on the political elites' model detected multicollinearity, and only the coefficients for public volume are reported in the table (media volume dropped from analysis).
} 
Republicans, and 56.6 percent for Democrats. As such, our results suggest that Twitter volume was not a predictor of vote share beyond a more traditional measure of electoral victory: incumbency status (Jacobson \& Carson, 2015) for the 2014 mid-term elections.

\section{Discussion}

Digital trace data, a form of behavioral residue, provides a record of our online actions and communication. This is apparent in the vast archives of social media posts, particularly Twitter. Much of this data is fairly accessible to scholars, and political scientists have attempted to assess social media's impact on and contributions to electoral outcomes (e.g. Gayo-Avello, 2013; Jungherr, 2015; Mitchell \& Hitlin, 2013; Tumasjan, 2010). We aim to expand on this work by dividing Twitter into three distinct groups of participants (the media, political elites, and the general public) rather than treating Twitter users as a homogeneous group. Also, we conceptualize Twitter as both a tool for and object of communication across these three distinct user groups. This allows us to assess first how campaign activities and electoral antecedents relate to Twitter attention and secondly the extent to which attention on Twitter correlated with electoral outcomes while controlling for other factors that influence them both. We find that contextual characteristics are related to the volume of Twitter conversation about a candidate, but the volume of tweets was not associated with vote share.

We first take up what contextual race factors may drive political attention on Twitter across the news media, political actors, and the public. For all three groups, money spent and the competitiveness of the race are both significantly associated with the volume of tweets about a candidate. For the media, competitiveness of the race is a stronger predictor of tweet volume than for the public or political elites. This may be a reflection of the media's well-documented reliance on horse race reporting; on which increased competitiveness is associated with an 
increase in game-frame coverage (Dunaway \& Lawrence, 2015). For the public, as well as political elites, political attention to a candidate appears to be driven less by how close the race is and more by the money spent campaigning.

Incumbents appear to have no advantages over their challengers on social media, at least in terms of generating significant tweet activity. Some observers see significant and increasing anti-establishment sentiment in recent U.S. elections (Kurtzleben, 2016), and indeed, 16 incumbents lost their seats in the election this study covered - about half of the 35 open seats. This may contribute to the lack of any significant relationships involving incumbency. This result should be interpreted cautiously in light of the possibility that it may be affected by shifts in political viewpoints that favor so-called insurgent candidates.

The volume of conversation about a candidate among the three groups is also highly correlated, including a nearly perfect correlation $(\mathrm{r}=.911)$ between the volume of media conversation and the volume of the public conversation. These findings offer support for Margolin et al.'s (2015) suggestion that posting content online is not necessarily a viable election predictor but rather a "response to the political information environment" (p. 13). They suggest that posts from the public are the result of a self-reinforcing feedback loop within news media and socio-technical systems. Feedback loops and interdependency between media systems is indicative of what Chadwick (2013) terms the hybrid media system. Future studies should continue to assess this hybrid nature with the aim of better understanding under which circumstances different actors/institutions in the system exert more influence or control over others. For example, researchers should investigate how traditional media attention towards a candidate might drive Twitter attention among the three groups we examine here. Others adopting our non-homogenous model for examining Twitter use in elections may examine these 
groups with more nuances, examining the differences among the news media and political elites - for example, between Republicans and Democrats.

Our null findings are also of interest and because only a few previous studies have previously reported them, we recognize that they are exploratory in nature (Fanelli, 2010; see also Jungherr, 2015). It's perhaps a little surprising that the volume of media tweets is not related to a candidate's vote share. First, traditional political science models often find media coverage to be a positive predictor of electoral success. But perhaps the media coverage itself has never been the endpoint. Rather, media coverage may be valuable to the extent it reaches the general public. This may help explain why campaigns direct considerable resources in attempts to influence the coverage of their candidate via strategic tweeting (Kreiss, 2014; Stromer-Galley, 2014). While some studies have shown that this "works" for campaigns in more traditional media (Heim, 2013), it may work differently on Twitter. Even as journalists use Twitter to gather political information and participate in the political process (Lawrence, Molyneux, Coddington \& Holton; Mourao, 2015) they may no longer be the primary source of messaging about a campaign. Consumers respond to social media messages from media, political actors and their own social networks, with their Twitter output potentially being influenced by all these groups.

One limitation is that we did not confine our data collection to tweets that were geotagged. As Gayo-Avello (2013) and others have pointed out, geotagging may be particularly important in studies employing a global language, like English, and when studying elections where interest is likely to expand beyond state borders (like the U.S. or the UK). Hence, we accept that there may be tweets from users, especially in the "public" data set, that are not 
necessarily U.S. voters. However, since our aim is not to provide a polling model, we find the geolocation issue to be of less importance in our case.

One of the main contributions of this paper to future scholarship is the non-homogeneous approach we introduce here to analyze other political phenomena. Future studies should employ this approach especially in the case of non-staged political events (e.g. protests and natural disasters). For protests, a research design should consider the social media content generated by the media, the government and activists, and separately assess their impact on the activation of master frames and number of people in the streets. For natural disasters, an analysis dividing content generated by public, media and official sources can generate insight into the information flow and the way social media may (or may not) disrupt gatekeeping processes during breaking news.

Our study purposefully avoids sweeping prediction claims, a valid criticism of much of the research in this area. Rather, we aimed only to assess how closely contextual variables relate to the volume of tweets about candidates, and in turn, how the volume of those tweets are related to electoral outcomes. We posit that the role of Twitter in politics may be best understood by breaking users into groups: the news media, political elites, and the public. Especially during elections, we argue that Twitter can be understood as a tool for and object of political communication. Our assessment of more than 3 million tweets about the 2014 elections suggests that Twitter is best understood as an outcome variable associated with other political contextual variables, as a tool for political communication, rather than as an object that yields the power to predict real-world electoral results. 


\section{Works Cited}

Abramowitz, A. I. (1988). Explaining senate election outcomes. American Political Science Review, 82(02), 385-403.

Barthel, M., Shearer, E., Gottfried, J. \& Mitchell, A. (2015). The evolving role of news on Twitter and Facebook. July 14. http://www.journalism.org/2015/07/14/the-evolving-role-ofnews-on-twitter-and-facebook/

Barthel, M. \& Shearer, E. (2015). How do Americans use Twitter for news? August 19. http://www.pewresearch.org/fact-tank/2015/08/19/how-do-americans-use-twitter-for-news

Bode, L., \& Epstein, B. (2015). Campaign Klout: Measuring Online Influence During the 2012 Election. Journal of Information Technology \& Politics, (ahead-of-print), 1-16.

Campbell, J. E. (2012). Forecasting the presidential and congressional elections of 2012: The trial-heat and the seats-in-trouble models. PS: Political Science \& Politics, 45(04), 630-634.

Chadwick, A. (2013). The hybrid media system: Politics and power. Oxford University Press.

Cision (2015). 2015 Global Social Journalism Study, conducted in partnership with Canterbury Christ Church University. Accessed August 17, 2016 at http://www.cision.com/us/resources/white-papers/2015-global-social-journalismstudy/?clid=whitepaper-ty

Coe, K., Kenski, K., \& Rains, S. A. (2014). Online and uncivil? Patterns and determinants of incivility in newspaper website comments. Journal of Communication, 64(4), 658-679.

Colleoni, E., Rozza, A., \& Arvidsson, A. (2014). Echo chamber or public sphere? Predicting political orientation and measuring political homophily in Twitter using big data. Journal of Communication, 64(2), 317-332.

Conover, M. D., Gonçalves, B., Flammini, A., \& Menczer, F. (2012). Partisan asymmetries in online political activity. EPJ Data Science, 1(1), 1.

Crimson Hexagon (n.d.) What is Auto-Sentiment? Crimson Hexagon Help Center. Accessed Aug. 21, 2015 at https://crimsonhexagon.zendesk.com/hc/en-us/articles/203523885-What-isAuto-Sentiment-.

Cummings, M. C. (1966). Congressmen and the Electorate; Elections for the US House and the President, 1920-1964. Free Press.

Dunaway, J., \& Lawrence, R. G. (2015). What predicts the game frame? Media ownership, electoral context, and campaign news. Political Communication, 32(1), 43-60.

Erikson, R. S. (1971). The advantage of incumbency in congressional elections. Polity, 395-405.

Erikson, R. S., \& Palfrey, T. R. (1998). Campaign spending and incumbency: An alternative simultaneous equations approach. The Journal of Politics, 60(02), 355-373.

Fanelli, D. (2010). Do pressures to publish increase scientists' bias? An empirical support from US States Data. PloS one, 5(4), e10271.

Farhi, P. (2009). The Twitter Explosion. American Journalism Review, 31(3), 26-31.

Freelon, D., \& Karpf, D. (2015). Of big birds and bayonets: hybrid Twitter interactivity in the 2012 Presidential debates. Information, Communication \& Society, 18(4), 390-406. 
Gayo Avello, D., Metaxas, P. T., \& Mustafaraj, E. (2011). Limits of electoral predictions using twitter. In Proceedings of the Fifth International AAAI Conference on Weblogs and Social Media. Association for the Advancement of Artificial Intelligence.

Gayo-Avello, D. (2012). " I Wanted to Predict Elections with Twitter and all I got was this Lousy Paper"--A Balanced Survey on Election Prediction using Twitter Data. arXiv preprint arXiv:1204.6441.

Gainous, J., \& Wagner, K. M. (2014). Tweeting to power: The social media revolution in American politics. Oxford University Press.

Gayo-Avello, D. (2013). A meta-analysis of state-of-the-art electoral prediction from Twitter data. Social Science Computer Review, 0894439313493979.

Gerber, A. (1998). Estimating the effect of campaign spending on senate election outcomes using instrumental variables. American Political Science Review, 92(02), 401-411.

Gil de Zúñiga, H., Molyneux, L., \& Zheng, P. (2014). Social media, political expression, and political participation: Panel analysis of lagged and concurrent relationships. Journal of Communication, 64(4), 612-634.

Gil de Zúñiga, H., Garcia-Perdomo, V., \& McGregor, S. C. (2015). What is second screening? Exploring motivations of second screen use and its effect on online political participation. Journal of Communication, 65(5), 793-815.

Hermida, A. (2010). Twittering the News: the emergence of ambient journalism. Journalism Practice, 4(3), 297-308.

Hitlin, P. (2013). How Crimson Hexagon works. Pew Research Center. November 4. http://www.journalism.org/2013/11/04/methodology-crimson-hexagon/.

Holton, A. E., \& Lewis, S. C. (2011). Journalists, social media, and the use of humor on Twitter. Electronic Journal of Communication, 21(1/2).

Hopkins, D., \& King, G. (2010). A Method of Automated Nonparametric Content Analysis for Social Science. American Journal of Political Science, 54(1), 229-247.

Jacobson, G. C., \& Carson, J. L. (2015). The politics of congressional elections. Rowman \& Littlefield.

Jungherr, A., Jürgens, P., \& Schoen, H. (2012). Why the pirate party won the German election of 2009 or the trouble with predictions: A response to Tumasjan, A., Sprenger, T.O., Sander, P.G., \& Welpe, I.M. "Predicting elections with Twitter: What 140 characters reveal about political sentiment”. Social Science Computer Review, 30(2), 229-234.

Jungherr, A. (2015). Analyzing Political Communication with Digital Trace Data. Springer.

Jungherr, A., Schoen, H., Posegga, O. \& Jurgens, P. (2016). Digital trace data in the study of public opinion: An indicator of attention toward politics rather than political support. Social Science Computer Review. (online ahead of print)

Kreiss, D. (2014). Seizing the moment: The presidential campaigns' use of Twitter during the 2012 electoral cycle. New Media \& Society, 1461444814562445. 
Kurtzleben, D. (2016). People Keep Talking About "The Establishment." What Is It, Anyway? NPR. Retrieved February 28, 2016, from http://www.npr.org/2016/02/11/466049701/howestablishment-became-the-buzzword-of-the-2016-election

Lasorsa, D. L., Lewis, S. C., \& Holton, A. E. (2012). Normalizing Twitter: Journalism practice in an emerging communication space. Journalism studies, 13(1), 19-36.

Lawrence, R. G., Molyneux, L., Coddington, M., \& Holton, A. (2014). Tweeting Conventions: Political journalists' use of Twitter to cover the 2012 presidential campaign. Journalism Studies, 15(6), 789-806.

Margolin, D. B., Goodman, S., Keegan, B., Lin, Y. R., \& Lazer, D. (2015). Wiki-worthy: collective judgment of candidate notability. Information, Communication \& Society, 1-17.

McGregor, S. C., Lawrence, R. G., \& Cardona, A. (2015, May). Personalization, gender, and social media: Gubernatorial candidates' social media strategies. Presented at 2015 ICA annual conference, San Juan, PR.

Mitchell, A. \& Hitlin, P. (2013). Twitter reaction to public events often at odds with overall public opinion. March 4. http://www.pewresearch.org/2013/03/04/twitter-reaction-to-eventsoften-at-odds-with-overall-public-opinion/

Morstatter, F., Pfeffer, J., Liu, H., \& Carley, K. M. (2013). Is the sample good enough? Comparing data from Twitter's streaming API with Twitter's firehose. In Proceedings the Seventh International AAAI Conference on Weblogs and Social Media, Boston, MA.

Mourão, R. R. (2015). The boys on the timeline: Political journalists' use of Twitter for building interpretive communities. Journalism, 16(8), 1107-1123.

Mourão, R., Diehl, T., \& Vasudevan, K. (2015). I Love Big Bird: How journalists tweeted humor during the 2012 presidential debates. Digital Journalism, 1-18.

Murthy, D. (2015). Twitter and elections: are tweets, predictive, reactive, or a form of buzz?. Information, Communication \& Society, 18(7), 816-831.

New York Times (2014). Senate Election Results. www.nytimes.com. Accessed Aug. 21, 2015 at http://elections.nytimes.com/2014/results/senate.

O'Connor, B., Balasubramanyan, R., Routledge, B. R., \& Smith, N. A. (2010). From tweets to polls: Linking text sentiment to public opinion time series. ICWSM, 11, 122-129.

Parmelee, J. H. (2013). The agenda-building function of political tweets. New Media \& Society, 1461444813487955.

Parmelee, J. H., \& Bichard, S. L. (2011). Politics and the Twitter revolution: How tweets influence the relationship between political leaders and the public. Lexington Books.

Pew Research Center (2016). The 2016 Presidential Campaign - a News Event That's Hard to Miss. Retrieved from http://www.journalism.org/2016/02/04/the-2016-presidentialcampaign-a-news-event-thats-hard-to-miss/

Stokes, D. E., \& Miller, W. E. (1962). Party government and the saliency of Congress. Public Opinion Quarterly, 26(4), 531-546.

Stromer-Galley, J. (2014). Presidential campaigning in the Internet age. Oxford University Press (UK). 
Tabachnick, B. G., \& Fidell, L. S. (2007). Using multivariate statistics, 5th.Needham Height, MA: Allyn \& Bacon.

Tumasjan, A., Sprenger, T. O., Sandner, P. G., \& Welpe, I. M. (2010). Predicting Elections with Twitter: What 140 Characters Reveal about Political Sentiment. ICWSM, 10, 178-185.

Wasike, B. S. (2013). Framing news in 140 characters: How social media editors frame the news and interact with audiences via Twitter. Global Media Journal, 6(1), 5.

Westlye, M. C. (1983). Competitiveness of Senate seats and voting behavior in Senate elections. American Journal of Political Science, 253-283.

Willis, D. (2014, November 4). Election Spending Is Changing, as Well as Expanding. The New York Times. Retrieved from http://www.nytimes.com/2014/11/05/upshot/election-spendingis-changing-not-just-getting-bigger.html?_r=0

Wu, S., Hofman, J. M., Mason, W. A., \& Watts, D. J. (2011, March). Who says what to whom on Twitter. In Proceedings of the 20th International conference on World Wide Web (pp. 705-714). ACM 